\title{
RC Beams Strengthened with FRP Plates. II: Analysis and PARAmetric Study
}

\author{
By Wei An,' Student Member, ASCE, Hamid Saadatmanesh, ${ }^{2}$ Associate \\ Member, ASCE, and Mohammad R. Ehsani, ${ }^{3}$ Member ASCE
}

\begin{abstract}
Analytical models based on the compatibility of deformations and equilibrium of forces are presented to predict the stresses and deformations in concrete beams strengthened with fiber composite plates epoxy-bonded to the tension face of the beams. The models are given for beams having rectangular and $\mathbf{T}$ cross sections. A parametric study is conducted to investigate the effects of design variables such as plate area, plate stiffness and strength, concrete compressive strength, and steel reinforcement ratio. The moment versus curvature diagrams for various combinations of these variables are plotted and compared. The results indicate that bonding composite plate to a concrete beam can increase the stiffness, yield moment, and flexural strength of the beam. The method is particularly effective for beams with a relatively low steel reinforcement ratio.
\end{abstract}

\section{INTRODUCTION}

A large number of bridges in the United States are either structurally deficient or functionally obsolete. To adequately serve present and future traffic needs, innovative and effective techniques need to be developed to strengthen these structures. Among the methods used to strengthen concrete bridges is the addition of epoxy-bonded steel plates to the tension flange. Bonding steel plates to the tension flange increases both the strength and stiffness of the girder and reduces cracks. This technique has been widely used in many countries, e.g., Australia, Japan, Switzerland, and South Africa. However, its application in the United States has been almost nonexistent (Klaiber et al. 1987). This strengthening method offers several advantages; (1) It is economical and can be rapidly applied in the field with little or no disturbance to bridge operation; (2) it does not alter the configuration of the structure; and (3) it does not reduce the overhead clearance. A disadvantage of this technique, however, is the corrosion of steel plate. Corrosion can damage the bond and eventually result in the failure of the structure. This problem can be avoided by using corrosion-resistant fiberreinforced-plastic (FRP) plate in lieu of steel plate. The effectiveness of such a technique has been demonstrated in an experimental investigation, which is summarized in an accompanying paper (Saadatmanesh and Ehsani 1991). This paper presents analytical models for predicting stresses and deformations in concrete beams externally reinforced with epoxy-bonded FRP plates. Fig. 1 shows cross sections of typical rectangular and T-beams that were used in the analytical study.

${ }^{1}$ Asst. Engr, , Boyle Engrg. Corp., Suite 250 North, 100 Howe Ave., Sacramento, CA 95825; formerly, Grad. Res. Asst., Dept. of Civ. Engrg, and Engrg. Mech., Univ. of Arizona, Tucson, AZ 85721.

${ }^{2}$ Asst. Prof., Dept. of Civ, Engrg. and Engrg. Mech., Univ. of Arizona, Tucson, AZ. AZ.

${ }^{3}$ Assoc. Prof., Dept. of Civ. Engrg. and Engrg. Mech., Univ. of Arizona, Tucson,

Note. Discussion open until April 1, 1992. Separate discussions should be submitted for the individual papers in this symposium. To extend the closing date one month, a written request must be filed with the ASCE Manager of Journals. The manuscript for this paper was submitted for review and possible publication on May 4, 1990. This paper is part of the Journal of Structural Engineering, Vol. 117, No. 11, November, 1991. CASCE, ISSN 0733-9445/91/0011-3434/\$1.00 + \$.15 per page. Paper No. 26386. 


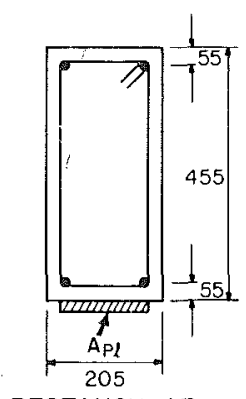

RECTANGULAR

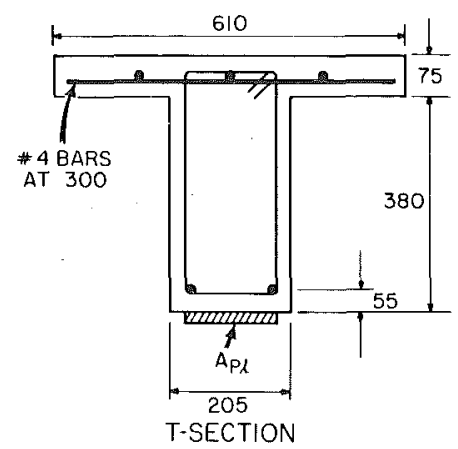

FIG. 1. Beam Cross Sections

\section{Previous Studies}

Very few analytical studies of concrete girders strengthened with epoxybonded steel plates are reported in the literature. No study of beams strengthened with fiber composite plates could be found.

Oehlers (1988) studied the flexural peeling stresses on the serviceability and ultimate strength of upgraded concrete beams. The failure of beams caused by large cracks in the concrete region between the plate and the longitudinal steel rebars was categorized in terms of forces that were present near the ends of the plates. Two distinct modes of failure were referred to: (1) Shear peeling, induced by the formation of shear diagonal cracks, which are associated with rapid separation of the plate; and (2) flexural peeling, induced by increasing curvature, which is associated with a gradual separation of the plate. The research was focused mainly on the problem of flexural peeling and the effect that shear forces had on flexural peeling up to the formation of diagonal shear cracks. Equations were developed to predict the ultimate peeling moment that causes the complete separation of the plate from the beam, and serviceability peeling moments that cause the initial formation of peeling cracks. It was concluded that the peeling strength depended on the flexural rigidity of the cracked plated section, the tensile strength of the concrete, and the thickness of the plate, and it did not depend on the previous loading history of the beam or the initial curvature of the beam.

Hamoush and Ahmad (1990) investigated the behavior of damaged concrete beams strengthened by externally bonded steel plates, using linearelastic fracture mechanics and the finite element method. The study investigated the failure by interface debonding of the steel plate and the adhesive layer as a result of interfacial shear stresses. Simply supported concrete beams under monotonically increasing symmetrical loads were considered in the study. The following parameters were studied: the effect of vertical flexural cracks in the concrete and the interfacial crack between the steel plate and the epoxy layer upon the ultimate load capacity, and the thickness of the epoxy layer and the position of the external load upon the changes in the strain energy release rate and the stress intensity factors. It was assumed that the horizontal interface cracks between the steel plate and adhesive layer were developed from the bottom tip of the flexural crack nearest to the support, and they extended horizontally outward toward the 
supports. They reached the following conclusions for the range of variables they studied: (1) For undamaged concrete beams, the strain energy release rate for an interface crack between steel plate and adhesive layer is negligibly small, and the steel plate-strengthened beam has high interface debonding load; (2) the strain energy release rate initially reaches a maximum value when the length of the interface crack is approximately equal to the length of the flexural cracks; (3) the existence of a larger number of flexural cracks (more than five) releases the shear stress at the interface, and that leads to the reduction in the strain energy release rate and stress intensity factors; (4) for the thicknesses of the adhesives studied $[2.5 \leq t \leq 6.35 \mathrm{~mm}(0.1 \leq$ $t \leq 0.25 \mathrm{in}$.)], no noticeable effect on the strain energy release rate and the stress intensity factors was observed.

\section{ObJectives}

Many factors affect the strength and ductility of beams strengthened with fiber composite plates. To address the effects of some of the basic design variables, this study focuses on the following objectives:

1. To present analytical models that predict the stresses and deformations in concrete beams strengthened with epoxy-bonded fiber composite plates in the elastic and inelastic regions.

2. To investigate the effects of design variables such as the steel reinforcement ratio, concrete compressive strength, plate area, and plate stiffness on the yield and ultimate moments of upgraded beams.

\section{Analysis}

Simplified analytical methods are developed to predict stresses and deformations in rectangular and T-beams strengthened with epoxy-bonded FRP plates. Fig. 1 shows the cross sections of the rectangular and T-beam that were used in the analytical study. The following assumptions are made in the analysis: (1) Linear strain distribution through the full depth of the beam; (2) small deformations; (3) no tensile strength in concrete; (4) no shear deformations; and (5) no slip between composite plate and concrete beam. It is further assumed that the area of the plate and, therefore, the ultimate force in the plate are sufficiently small so that shear failure of concrete layere between the plate and longitudinal steel rebars will not occur.

\section{Stress-Strain Curves}

The stress-strain relationship of steel rebar is assumed to be elastic-ideally plastic for purposes of analysis. Grade 60 steel with a yield stress of 414 MPa (60 ksi) is used in the analysis.

The glass-fiber-reinforced composites generally behave linearly elastic to failure. A wide range of composites with different mechanical properties is available. For the purposes of a parametric study, two combinations of ultimate strength and modulus of elasticity are used for the composite plate: $F_{p}=414 \mathrm{MPa}(60 \mathrm{ksi})$ with $E_{p}=34.5 \mathrm{GPa}(5,000 \mathrm{ksi})$, and $F_{p}=827 \mathrm{MPa}$ $(120 \mathrm{ksi})$ with $E_{p}=68.9 \mathrm{GPa}(10,000 \mathrm{ksi})$, where $F_{p}=$ ultimate strength of composite plate; and $E_{p}=$ modulus of elasticity of composite plate.

Hognestad's parabola of idealized stress-strain curve for concrete in un- 
iaxial compression is used (Park and Paulay 1975). Fig. 2 shows the stressstrain curve of concrete, where $f_{c}^{\prime \prime}=k f_{c}^{\prime}, k=0.92$ for $f_{c}^{\prime}=34.5 \mathrm{GPa}(5,000$ ksi) (Park and Paulay 1975); $f_{c}^{\prime}=$ concrete compressive strength; $f_{c}=$ stress in concrete; $\varepsilon_{o}=$ strain in concrete at maximum stress; $\varepsilon_{c}=$ strain in concrete; and $E_{c}=$ initial tangent modulus of concrete.

\section{Calculation of Strains, Stresses, and Curvature}

The strains and stresses in the FRP plate, steel rebar, and concrete, as well as the curvature at midspan, are calculated using an incremental deformation technique described in the following. For the convenience of calculations, strain in the extreme fiber of concrete $\varepsilon_{c f}$, rather than the load, is increased in specified increments to generate the moment-curvature curves.

Fig. 3 shows the strains and stresses across the depth of a typical rectangular beam with a composite plate bonded to the tension face. The strain in the extreme fiber of concrete in compression at midspan $\varepsilon_{c f}$ is increased until failure is reached. It is assumed that failure is reached when either the concrete strain reaches 0.003 or the composite plate reaches its ultimate strain. Next, strains in the rebars and composite plate are calculated in terms of $\varepsilon_{c f}$ from the following equations

$\varepsilon_{s i}=\varepsilon_{c f} \frac{c-d_{i}}{c}$

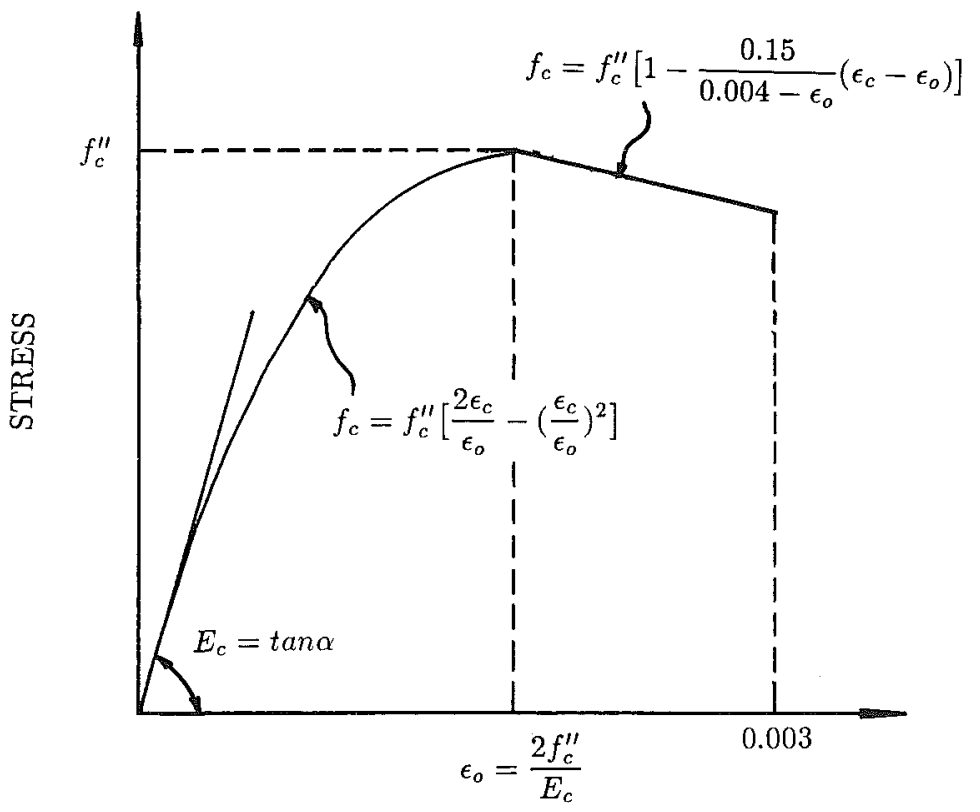

STRAIN

FIG. 2. Idealized Stress-Strain Curve for Concrete in Uniaxial Compression 


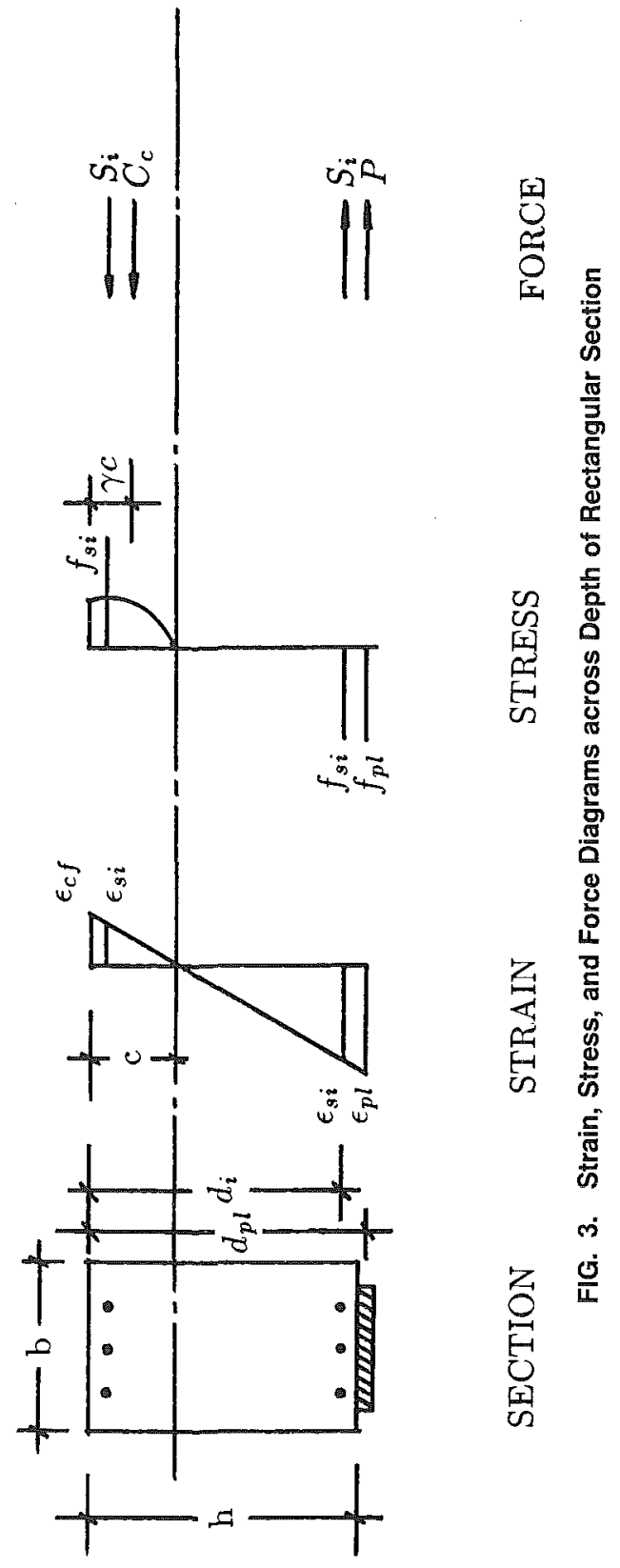


$\varepsilon_{p l}=\varepsilon_{c f} \frac{c-d_{p l}}{c}$

where $\varepsilon_{s i}=$ strain in steel rebar at level $i ; c=$ distance to neutral axis measured from top concrete fiber; $d_{i}=$ distance from top concrete fiber to centroid of steel rebar in layer $i$; $\varepsilon_{p l}=$ strain in composite plate; and $d_{p l}=$ distance from top concrete fiber to centroid of composite plate.

The steel stresses $f_{s i}$ and plate stress $f_{p l}$ corresponding to strains $\varepsilon_{s i}$ and $\varepsilon_{p l}$ are found from the stress-strain curves for steel and plate

$f_{s i}=E_{s} \varepsilon_{s i}, \quad$ if $\varepsilon_{s i} \leq \varepsilon_{y}$

$f_{s i}=f_{y}, \quad$ if $\varepsilon_{s i}>\varepsilon_{y}$

$f_{p l}=E_{p l} \varepsilon_{p l}$

where $E_{s}=$ modulus of elasticity of steel; $\varepsilon_{y}=$ yield strain of steel; $f_{y}=$ yield stress of steel; and $E_{p l}=$ modulus of elasticity of composite plate.

The steel forces $S_{i}$ and plate force, $P$ are found by multiplying the steel stresses by their corresponding areas and the plate stress by plate area, respectively

$S_{i}=f_{s i} A_{s i}$

$P=f_{p l} A_{p l}$

where $A_{s i}=$ total area of steel in layer $i$; and $A_{p l}=$ area of composite plate.

The distribution of concrete stresses in the compression zone is found from the stress-strain curve of concrete. The concrete stress-strain relationship is expressed as follows

$f_{c}=f_{c}^{\prime \prime}\left[2 \frac{\varepsilon_{c}}{\varepsilon_{o}}-\left(\frac{\varepsilon_{c}}{\varepsilon_{o}}\right)^{2}\right], \quad$ if $0 \leq \varepsilon_{c}<\varepsilon_{o}$

and

$f_{c}=f_{c}^{\prime \prime}\left[1-\frac{0.15}{0.004-\varepsilon_{o}}\left(\varepsilon_{c}-\varepsilon_{o}\right)\right], \quad$ if $\varepsilon_{o} \leq \varepsilon_{c} \leq 0.003$

For any given concrete strain in the extreme compression fiber $\varepsilon_{c f}$, the concrete compression force $C_{c}$ is expressed in terms of a parameter $\alpha$, defined as follows (Park and Paulay 1975)

$C_{c}=\alpha f_{c}^{\prime \prime} b c$

The parameter $\alpha$ (mean stress factor) is used to convert the nonlinear, stress-strain relationship of concrete into an equivalent rectangular stressstrain curve. It is calculated by equating the area under the stress-strain curve to an equivalent rectangular area

$A=\int_{0}^{\varepsilon_{c f}} f_{c} d \varepsilon_{c}=\alpha f_{c}^{\prime \prime} \varepsilon_{c f}$

where $A=$ area under stress-strain curve of concrete.

Then, $\alpha$ is obtained from 
$\alpha=\frac{\int_{0}^{\varepsilon_{c} f} f_{c} d \varepsilon_{c}}{f_{c}^{\prime \prime} \varepsilon_{c f}}$

Evaluating the right side of (12) results in the following values for $\alpha$

$\alpha=\frac{\varepsilon_{c f}}{\varepsilon_{o}}-\frac{\varepsilon_{c f}^{2}}{3 \varepsilon_{o}^{2}}, \quad$ if $0 \leq \varepsilon_{c f}<\varepsilon_{o}$

$\alpha=1+\frac{\varepsilon_{c f}}{\varepsilon_{o}}\left(1-\frac{\varepsilon_{c f}}{3 \varepsilon_{o}}-\frac{\varepsilon_{o}^{2}}{\varepsilon_{c f}^{2}}\right)-\frac{0.15}{0.004-\varepsilon_{o}}\left(\frac{\varepsilon_{c f}}{2}-\varepsilon_{o}\right)$

$-\frac{0.075}{0.004-\varepsilon_{o}}\left(\frac{\varepsilon_{o}^{2}}{\varepsilon_{c f}}\right), \quad$ if $\varepsilon_{o} \leq \varepsilon_{c f} \leq 0.003$

The position of concrete compressive force $C_{c}$, measured from the top fiber of concrete, is expressed in terms of the parameter $\gamma$, shown in Fig. 3 and calculated as follows

$d_{c}=\gamma c$

where $d_{c}=$ distance from top concrete fiber to line of action of concrete compressive force.

The first moment of area under the concrete stress-strain diagram about the origin $Q$ is given by

$Q=\int_{0}^{\varepsilon_{c} j} f_{c} \varepsilon_{c} d \varepsilon_{c}=\bar{\varepsilon}_{c} A$

where $\bar{\varepsilon}_{c}=$ strain at centroid of area under stress-strain diagram.

The strain at centroid $\bar{\varepsilon}_{c}$ can be defined in terms of $\varepsilon_{c f}$ by

$\bar{\varepsilon}_{c}=(1-\gamma) \varepsilon_{c f}$

and therefore

$Q=\bar{\varepsilon}_{c} A=(1-\gamma) \varepsilon_{c f} \int_{0}^{\varepsilon_{c f}} f_{c} d \varepsilon_{c}$

The parameter $\gamma$ (centroid factor) is obtained by equating (15) and (17)

$\gamma=1-\frac{\int_{0}^{\varepsilon_{c f}} \varepsilon_{c} f_{c} d \varepsilon_{c}}{\varepsilon_{c f} \int_{0}^{\varepsilon_{c f}} f_{c} d \varepsilon_{c}}$

Evaluating (18) results in the following values for $\gamma$

$\gamma=\frac{\frac{1}{3}-\frac{\varepsilon_{c f}}{12 \varepsilon_{o}}}{1-\frac{\varepsilon_{c f}}{3 \varepsilon_{o}}}, \quad$ if $0 \leq \varepsilon_{c f}<\varepsilon_{o}$

and 
$\gamma=1-\frac{\left(\varepsilon_{c f}^{3}-5.1 \varepsilon_{o} \varepsilon_{c f}^{2}-0.004 \varepsilon_{o}^{2}+0.024 \varepsilon_{c f}^{2}\right)}{\varepsilon_{c f}\left(3.925 \varepsilon_{o}^{2}-10.2 \varepsilon_{o} \varepsilon_{c f}-0.9 \varepsilon_{c f}^{2}-0.016 \varepsilon_{o}+0.048 \varepsilon_{c f}\right)}$,

if $\varepsilon_{o} \leq \varepsilon_{c f}<0.003$

The location of the neutral axis $c$ is obtained from the equilibrium of internal forces as given by (20). Eq. 20 is solved iteratively until the equilibrium of forces across the depth of the cross section is satisfied

$\alpha f_{c}^{\prime \prime} b c+\sum_{i=1}^{n} f_{s i} A_{s i}+f_{p l} A_{p l}=0$

The internal resisting moment is obtained by summing the moments of all internal force about an axis

$M=\alpha f_{c}^{\prime \prime} b c\left(\frac{h}{2}-\gamma c\right)+\sum_{i=1}^{n} f_{s i} A_{s i}\left(\frac{h}{2}-d_{i}\right)+f_{p l} A_{p l}\left(\frac{h}{2}-d_{p l}\right) \ldots \ldots$

The curvature at midspan is calculated by dividing the concrete strain $\varepsilon_{c f}$ by the distance to the neutral axis $c$

$\phi=\frac{\varepsilon_{c f}}{c}$

The moment and curvature at the midspan of beams with $\mathrm{T}$ cross sections are calculated using the equations just presented when the neutral axis falls within the thickness of the flange. However, for the case in which the neutral axis falls within the web, parameters $\alpha$ and $\gamma$ must be redefined to incorporate the effect of change in the width of the cross section at the flangeweb junction. Fig. 4 shows the strains and stresses across the depth of the T-beam for the case in which the neutral axis falls within the web, where $\varepsilon_{h_{1}}=$ strain at the flange-web junction.

Depending on the relative magnitudes of $\varepsilon_{h_{1}}, \varepsilon_{o}$, and $\varepsilon_{c f}$, three cases must be considered for calculations of parameters $\alpha$ and $\gamma$. The expressions for these parameters are given in the following. In each case, the compressive force in the concrete is divided into two components: one acting in the web $C_{c_{1}}$, and the other acting in the flange $C_{c_{2}}$ and, therefore, for each force component two sets of parameters $\alpha$ and $\gamma$ are given

Case 1: $0 \leq \varepsilon_{c f}<\varepsilon_{o}$

$\alpha_{f}=\frac{1}{\varepsilon_{c f}}\left[\frac{\varepsilon_{c f}^{2}}{\varepsilon_{o}}\left(1-\frac{\varepsilon_{c f}}{3 \varepsilon_{o}}\right)-\frac{\varepsilon_{h_{1}}^{2}}{\varepsilon_{o}}\left(1-\frac{\varepsilon_{h_{1}}}{3 \varepsilon_{o}}\right)\right] \ldots \ldots \ldots \ldots \ldots \ldots \ldots \ldots$
$\gamma_{f}=1-\frac{\varepsilon_{c f}^{3}\left(\frac{2}{3}-\frac{\varepsilon_{c f}}{4 \varepsilon_{o}}\right)-\varepsilon_{h_{1}}^{3}\left(\frac{2}{3}-\frac{\varepsilon_{h_{1}}}{4 \varepsilon_{o}}\right)}{\left(\varepsilon_{c f}-\varepsilon_{h_{1}}\right)\left[\varepsilon_{c f}^{2}\left(1-\frac{\varepsilon_{c f}}{3 \varepsilon_{o}}\right)-\varepsilon_{h_{1}}^{2}\left(1-\frac{\varepsilon_{h 1}}{3 \varepsilon_{o}}\right)\right]}+\frac{\varepsilon_{h_{1}}}{\varepsilon_{c f}-\varepsilon_{h_{1}}} \ldots \ldots$

$\alpha_{w}=\frac{\varepsilon_{h_{1}}^{2}}{\varepsilon_{c f} \varepsilon_{o}}\left(1-\frac{\varepsilon_{h_{1}}}{3 \varepsilon_{o}}\right)$ 


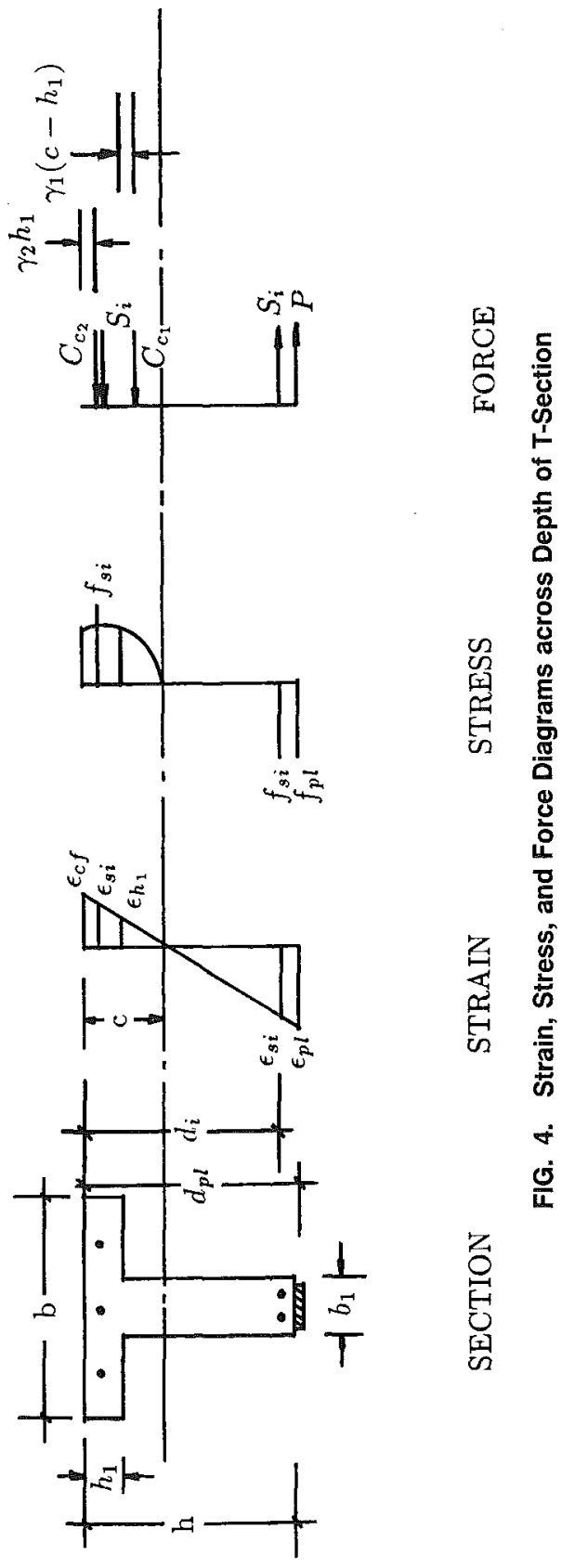


$\gamma_{w^{\prime}}=1-\frac{\frac{2}{3}-\frac{\varepsilon_{h_{1}}}{4 \varepsilon_{o}}}{1-\frac{\varepsilon_{h_{1}}}{3 \varepsilon_{o}}}$

where subscripts $f$ and $w=$ parameters calculated for the component of the force in the flange and web, respectively.

Case 2: $0 \leq \varepsilon_{h 1}<\varepsilon_{o}$ and $\varepsilon_{o} \leq \varepsilon_{c f} \leq 0.003$

$\alpha_{f}=\frac{1}{\varepsilon_{c f}}\left[\frac{\varepsilon_{h h_{1}}^{3}}{3 \varepsilon_{o}^{2}}-\frac{\varepsilon_{h_{1}}^{2}}{\varepsilon_{o}}-\frac{1}{3} \varepsilon_{o}+\varepsilon_{c f}-\frac{0.15}{0.004-\varepsilon_{o}}\right.$

$\left.\left(\frac{1}{2} \varepsilon_{c f}^{2}-\varepsilon_{c f} \varepsilon_{o}+\frac{1}{2} \varepsilon_{o}^{2}\right)\right]$

$\gamma_{f}=1+\frac{\left(\varepsilon_{o}^{4}+8 \varepsilon_{o} \varepsilon_{h 1}^{3}-3 \varepsilon_{h 1}^{4}-6 \varepsilon_{o}^{2} \varepsilon_{c f}^{2}\right)+A\left(4 \varepsilon_{c f}^{3}-6 \varepsilon_{o} \varepsilon_{c f}^{2}+2 \varepsilon_{o}^{3}\right)}{\left(\varepsilon_{c f}-\varepsilon_{h 1}\right)\left[B-A\left(6 \varepsilon_{c f}^{2}-12 \varepsilon_{o} \varepsilon_{c f}+6 \varepsilon_{o}^{2}\right)\right]}$

$+\frac{\varepsilon_{h_{1}}}{\varepsilon_{c f}-\varepsilon_{h_{1}}}$

where

$A=\frac{0.15 \varepsilon_{o}^{2}}{0.004-\varepsilon_{o}}$

$B=12 \varepsilon_{o}^{2} \varepsilon_{c f}+4 \varepsilon_{h_{1}}^{3}-4 \varepsilon_{o}^{3}-12 \varepsilon_{h_{1}}^{2} \varepsilon_{o}$

$\alpha_{w^{\prime}}=\frac{\varepsilon_{h_{11}}^{2}}{\varepsilon_{c f} \varepsilon_{o}}\left(1-\frac{\varepsilon_{h_{1}}}{3 \varepsilon_{o}}\right)$

$\gamma_{w}=1-\frac{\frac{2}{3}-\frac{\varepsilon_{h_{1}}}{4 \varepsilon_{o}}}{1-\frac{\varepsilon_{h_{1}}}{3 \varepsilon_{o}}}$

Case 3: $\varepsilon_{h 1} \geq \varepsilon_{o}$ and $\varepsilon_{c f} \geq \varepsilon_{o}$

$\alpha_{f}=\frac{1}{\varepsilon_{c f}}$

$\left[\left(\varepsilon_{c f}-\varepsilon_{h 1}\right)-\frac{0.15}{0.004-\varepsilon_{o}}\left(\frac{1}{2} \varepsilon_{c f}^{2}-\varepsilon_{o} \varepsilon_{c f}+\varepsilon_{o} \varepsilon_{h_{1}}-\frac{1}{2} \varepsilon_{h_{1}}^{2}\right)\right]$

$\gamma_{f}=1-$

$$
3\left(\varepsilon_{c f}^{2}-\varepsilon_{h 1}^{2}\right)-\frac{0.15}{0.004-\varepsilon_{o}}\left(2 \varepsilon_{c f}^{3}-3 \varepsilon_{o} \varepsilon_{c f}^{2}+3 \varepsilon_{o} \varepsilon_{h 1}^{2}-2 \varepsilon_{h 1}^{3}\right)
$$

$\overline{\left(\varepsilon_{c f}+\varepsilon_{h 1}\right)\left[6\left(\varepsilon_{c f}-\varepsilon_{h 1}\right)-\frac{0.15}{0.004-\varepsilon_{o}}\left(3 \varepsilon_{c f}^{2}-6 \varepsilon_{o} \varepsilon_{c f}+6 \varepsilon_{o} \varepsilon_{h 1}-3 \varepsilon_{h 1}^{2}\right)\right]}$

$+\frac{\varepsilon_{h_{1}}}{\varepsilon_{c f}-\varepsilon_{h_{1}}}$ 


$$
\begin{aligned}
& \alpha_{w}=\frac{1}{\varepsilon_{c f}}\left[\left(\varepsilon_{h_{1}}-\frac{1}{3} \varepsilon_{o}\right)-\frac{0.15}{0.004-\varepsilon_{o}}\left(\frac{1}{2} \varepsilon_{h 1}^{2}-\varepsilon_{o} \varepsilon_{h_{1}}+\frac{1}{2} \varepsilon_{o}^{2}\right)\right] \ldots \\
& \gamma_{w}=1-\frac{\left(\frac{1}{2} \varepsilon_{h 1}^{2}-\frac{1}{12} \varepsilon_{o}^{2}\right)-\frac{0.15}{0.004-\varepsilon_{o}}\left(\frac{1}{3} \varepsilon_{h_{1}}^{3}-\frac{1}{2} \varepsilon_{o} \varepsilon_{h 1}^{2}+\frac{1}{6} \varepsilon_{o}^{3}\right)}{\varepsilon_{h 1}\left[\left(\varepsilon_{h 1}-\frac{1}{3} \varepsilon_{o}\right)-\frac{0.15}{0.004-\varepsilon_{o}}\left(\frac{1}{2} \varepsilon_{h_{11}}^{2}-\varepsilon_{o} \varepsilon_{h 1}+\frac{1}{2} \varepsilon_{o}^{2}\right)\right]} \ldots
\end{aligned}
$$

The location of the neutral axis is obtained from the equilibrium of forces across the depth of the cross section similar to that for the rectangular section. The internal resisting moment and curvature also are obtained in the same manner as those for the rectangular section.

A computer program was developed to carry out the numerical calculations. The results of the analytical models were compared with test results of several retrofitted concrete beams. Generally, the measured and analytical results correlated well (Saadatmanesh and Ehsani 1991).

\section{Parametric Study}

To investigate the effects of design variables such as steel reinforcement ratio, plate area, plate ultimate strength and stiffness, and concrete compressive strength on the moment-curvature relationship of upgraded beams, a parametric study was conducted. The moment-curvature diagrams are generated for rectangular and T-sections, shown in Figs. 1( $\mathrm{a}$ and $\mathrm{b}$ ), respectively. In the plots, each curve is identified with an acronym, where the first symbol stands for the cross section type, i.e., $\mathrm{R}=$ rectangular beam and $\mathrm{T}=\mathrm{T}$-beam; the second symbol stands for compressive strength of concrete, i.e., 3 indicates $20.6 \mathrm{MPa}(3,000 \mathrm{psi})$ and 6 indicates $41.4 \mathrm{MPa}$ $(6,000 \mathrm{psi})$; the third symbol stands for reinforcement ratio, i.e., L indicates a low reinforcement ratio or $\rho=0.005$ and $H$ indicates a high reinforcement ratio or $\rho=0.015$; the fourth symbol stands for the combination of modulus of elasticity and ultimate strength of plate, i.e., 5 indicates $E_{p}=34.5 \mathrm{GPa}$ $(5,000 \mathrm{ksi})$ and $F_{p}=414 \mathrm{MPa}(60 \mathrm{ksi})$ and 10 indicates $E_{p}=68.9 \mathrm{GPa}$ $(10,000 \mathrm{ksi})$ and $F_{p}=828 \mathrm{MPa}(120 \mathrm{ksi})$; finally, the last symbol indicates the ratio of plate area to gross area of concrete, i.e., L indicates $A_{p l} / b h=$ $0.0025 ; \mathrm{M}$ indicates $A_{p l} / b h=0.005 ;$ and $\mathrm{H}$ indicates $A_{p l} / b h=0.015$, where $b=$ width of web; and $h=$ height of cross section. Each curve is terminated either when concrete in compression reaches a strain of 0.003 or when the composite plate reaches its ultimate strength.

\section{Rectangular Beams}

Fig. 5 shows the moment versus curvature diagrams for the section with three different ratios of plate area to gross concrete section, i.e., $A_{p l} / b h=$ $0.0025,0.005$, and 0.015 . The remaining parameters are held constant at the following values: $f_{c}^{\prime}=20.7 \mathrm{MPa}(3,000 \mathrm{psi}) ; \rho=0.005 ; F_{p}=414 \mathrm{MPa}$ $(60 \mathrm{ksi})$; and $E_{p}=34.5 \mathrm{GPa}(5,000 \mathrm{ksi})$. In addition, the moment versus curvature for the same section without plate is plotted with dashed-dotted lines. The low reinforcement ratio of this beam is intended to represent a beam designed with insufficient flexural steel or one in which corrosion has caused a significant reduction in the area of tension reinforcement. It can 


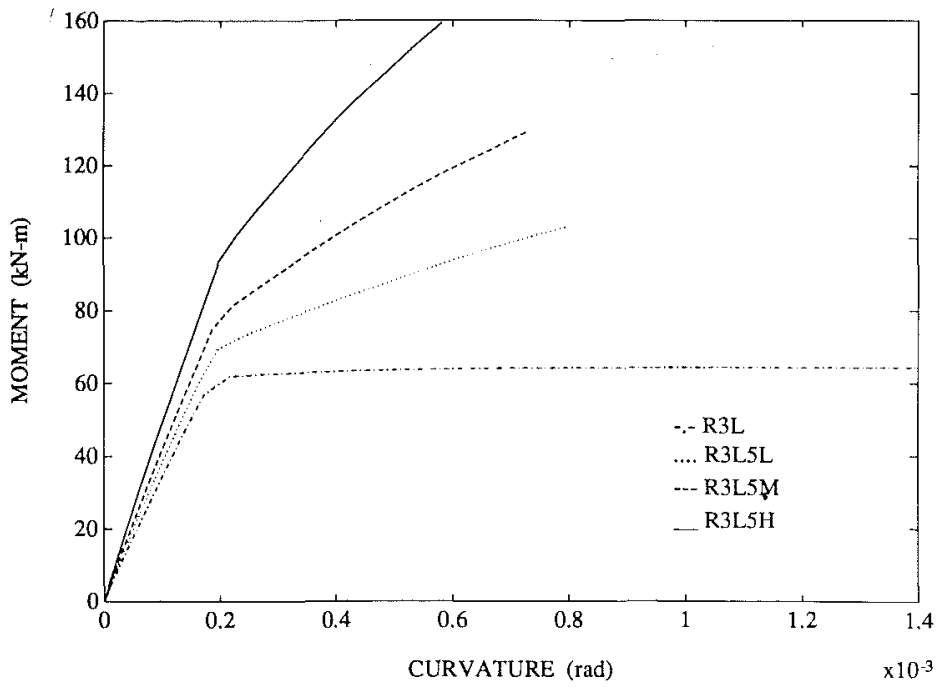

FIG. 5. Moment versus Curvature (Beams R3L, R3L5L, R3L5M, and R3L5H)

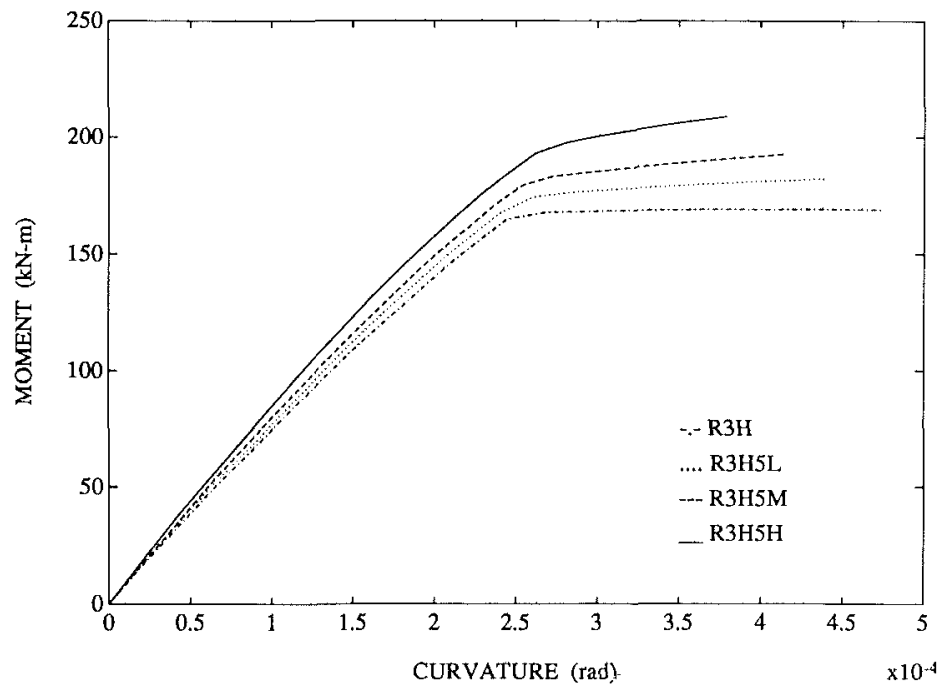

FIG. 6. Moment versus Curvature (Beams R3H, R3H5L, R3H5M, and R3H5H) 
be seen from the figures that the addition of composite plate to the section significantly increases the yield and ultimate moments. The stiffness of the section also is increased as a result of plating. The failure in each case resulted from crushing of concrete at a strain of 0.003 . Fig. 5 also shows that the curvature at failure reduces as the area of plate increases; however, the area under moment-curvature diagram does not decrease appreciably.

Fig. 6 shows the moment-curvature diagrams of the beam with the same three ratios of plate area to gross concrete area. All other variables are the same as those in Fig. 5 except the reinforcement ratio. In this case, the beam has a higher steel reinforcement ratio, i.e., $\rho=0.015$. As can be seen from Fig. 6, the gain in the yield and ultimate moments, beyond those for the beam without plate, are not as significant as those in the previous case in which the beam had a smaller steel reinforcement ratio. The reason is that the compressive component of the internal moment couple delivered by concrete cannot be increased beyond a certain limit due to crushing of concrete. This also limits the tensile component of the internal moment provided by the combined action of the plate and steel rebar. As a result, the plate in this case could not be used as effectively as that in the previous case. This cannot, however, be considered a major disadvantage because this technique will be used when there is a lack of sufficient reinforcement in the beam. Also, the results of moment versus curvature diagrams show that for beams with high steel reinforcement ratio, a stiffer plate in combination with a higher strength concrete will be more effective, as can be seen from the plots in Fig. 7. The steel reinforcement ratio in this beam is the same as that for the beam in Fig. 6; however, because of the higher strength of plate and and concrete, the relative gains in the yield and ultimate moments are greater than those in the previous case.

The effect of an increase in compressive strength of concrete on the moment-curvature behavior of the section also is shown in Fig. 8. The design variables of this beam are the same as those for the beam in Fig. 5 except the concrete compressive strength is doubled. Comparison of Fig. 5 and 8 shows that increasing the compressive strength in combination with the addition of the composite plate significantly increases the ultimate moment of the beam beyond those in Fig. 5 . This is because of an additional internal moment couple produced by the tensile forces in the plate and rebar and an equal compressive force delivered by the higher strength concrete. The failure in each occurred when the plate reached its ultimate strength. The upgraded beams show less ductility than the beam without plate.

Fig. 9 shows the moment versus curvature diagrams for beams with low reinforcement ratio and concrete compressive strength, but with plates of high modulus and ultimate strength for the three different plate area-togross-concrete-area ratios. As was observed in Fig. 5, it can be seen that plating significantly increases the yield and ultimate moments beyond their original values, particularly when a stiff strong plate is used in beams with a relatively low reinforcement ratio.

Fig. 10 shows the increase in the ultimate moment of beams as a function of plate area. The dashed line indicates the increase in moment for composite plate with $E_{p}=34.5 \mathrm{GPa}(5,000 \mathrm{ksi})$ and $F_{p}=414 \mathrm{MPa}(60 \mathrm{ksi})$. The solid line indicates the increase in moment capacity for composite plate with $E_{p}=68.9 \mathrm{GPa}(10,000 \mathrm{ksi})$ and $F_{p}=828 \mathrm{MPa}(120 \mathrm{ksi})$. Five different ratios of plate area to gross concrete section were used in this plot; namely, $A_{p l} / b h=0 ., 0.0025,0.005,0.010$, and 0.015 . For both types of plates, the ultimate moment capacity increases as the plate area increases. However, 


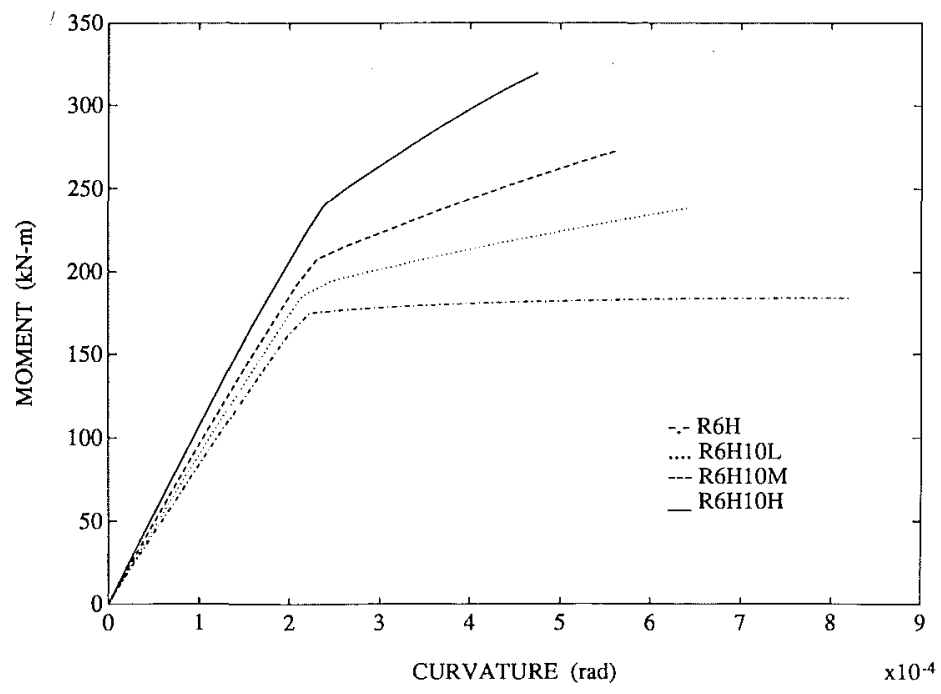

FIG. 7. Moment versus Curvature (Beams R6H, R6H10L, R6H10M, and R6H10H)

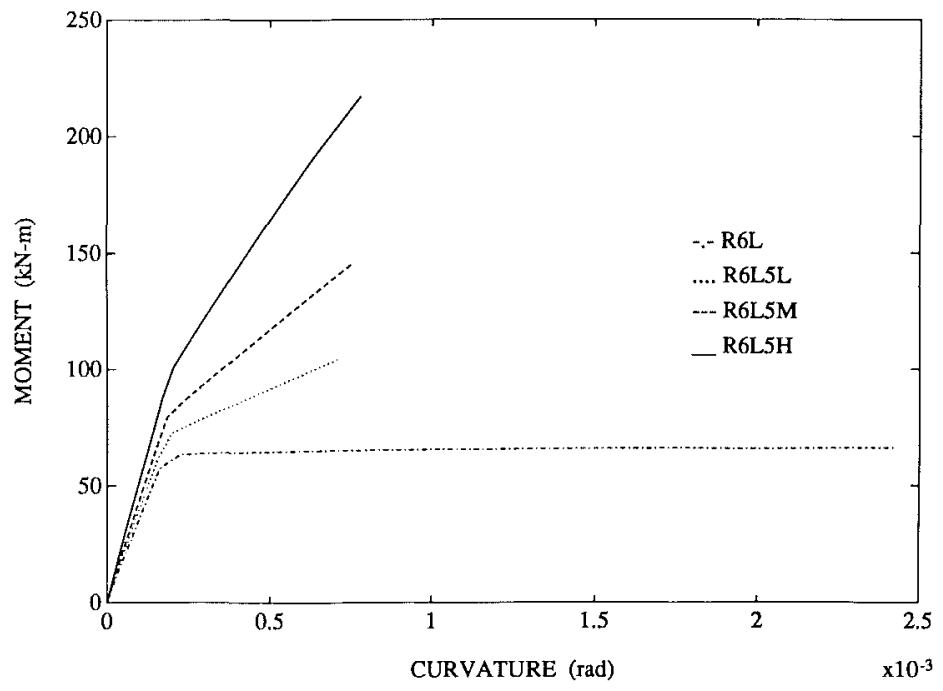

FIG. 8. Moment versus Curvature (Beams R6L, R6L10L, R6L10M, and R6L10H) 


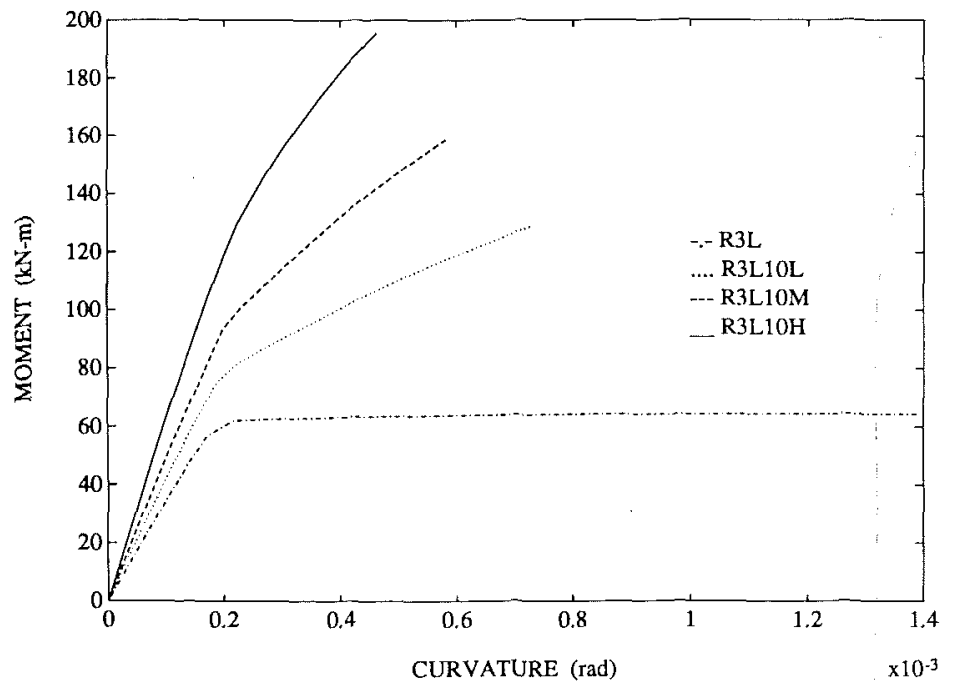

FIG. 9. Moment versus Curvature (Beams R3L, R3L10L, R3L10M, and R3L10H)

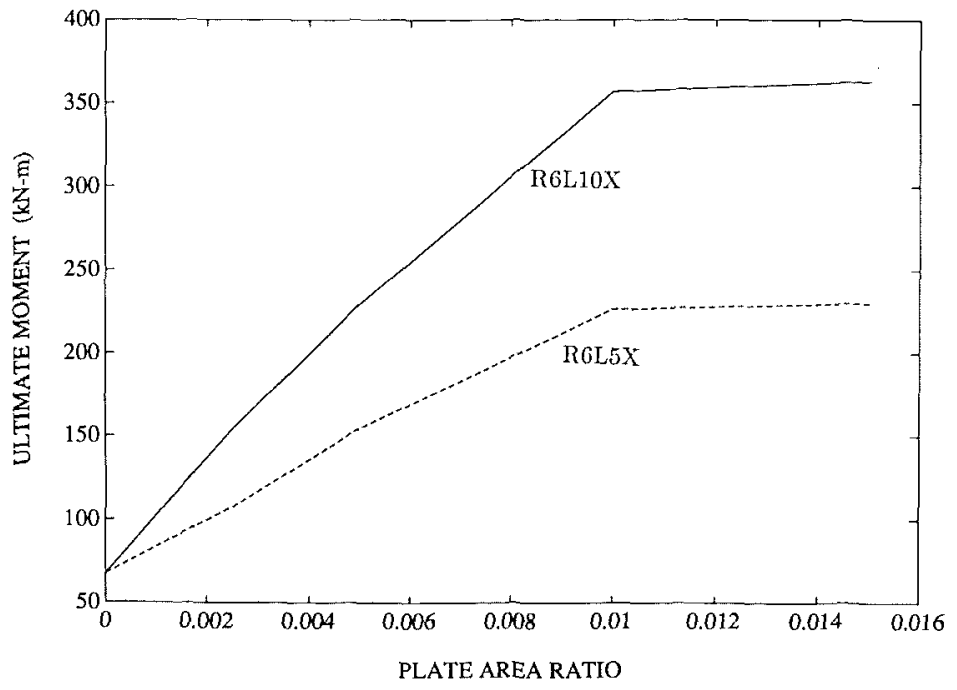

FIG. 10. Ultimate Moment versus Ratio of Plate Area to Gross Concrete Area (Rectangular Beam) 
the rate of increase in the ultimate moment capacity decreases as the plate area increases.

Fig. 11 shows the relationship between the ultimate moment and reinforcement ratio for four beams with $A_{p l} / b h=0 ., 0.0025,0.005$, and 0.015 . The ultimate moment increases as a result of an increase in both the reinforcement ratio $\rho$ and the ratio of plate area to gross concrete section. However, the rate of increase in the moment capacity reduces as the plate area increases, as can be seen from the reduction in the slopes of the curves from the bottom to the top of the figure. In these plots, three different reinforcement ratios were used to generate each curve, i.e., $\rho=0.005$, 0.010 , and 0.015 .

Fig. 12 shows the effect of an increase in the compressive strength of concrete on the ultimate capacities of beams with no plate and beams with the three different ratios of plate area. Increasing the concrete compressive strength only slightly increased the ultimate capacity of the beam with no plate. However, for the upgraded beams, as the plate area increases the rate of increase in moment capacity increases, as can be seen from the increasing slopes of the curves from bottom to top in Fig. 12. This behavior of the upgraded beams can be particularly useful in older bridges where the deck must be replaced. Using higher strength concrete for the replacement deck in such cases in combination with composite plates bonded to the tension face of the girders can significantly increase the ultimate moment capacity of the bridge.

\section{T-BEAmS}

The moment versus curvature diagrams for the cross section shown in Fig. $(1 b)$ are plotted for the same design variables as those for the rectangular beam.

Fig. 13 shows the moment versus curvature diagram for the T-beam for four different ratios of plate area, namely, $A_{p l} / b h=0,0.0025,0.005$, and 0.015 , where $b=$ the width of the web. Other design variables are held constant at the following values: $f_{c}^{\prime}=20.7 \mathrm{MPa}(3,000 \mathrm{psi}) ; \rho=0.005 ; F_{p}$ $=414 \mathrm{MPa}(60 \mathrm{ksi})$; and $E_{p}=34.5 \mathrm{GPa}(5,000 \mathrm{ksi})$. Fig. 13 shows that adding a composite plate to the section increases the yield and ultimate moments of the section and reduces the curvature at failure. The failure in this case was reached as a result of the composite plate reaching its ultimate strength. The reason for this failure mode was the position of the neutral axis, which was relatively closer to the top flange for the T-beam compared with that of the rectangular beam. This resulted in a longer distance between the neutral axis and the composite plate and, consequently, larger strains in the plate, which eventually resulted in the failure of the plate before crushing of concrete.

Fig. 14 shows the moment-curvature diagram of the T-beam with all design parameters the same as those for the beam in Fig. 13 except a higher reinforcement ratio, $\rho=0.015$. The behavior of the upgraded beam was similar to the beam in the previous figure; i.e., failure was reached when the composite plate failed. Adding a composite plate to the beam increased the yield and ultimate moments. However, the relative increase in these moments was not as significant as those for the beam that had lower steel reinforcement ratio (Fig. 13). Similar results also were observed for the rectangular beam discussed in the previous section.

Fig. 15 shows the increase in the ultimate moment capacity of the T-beam 


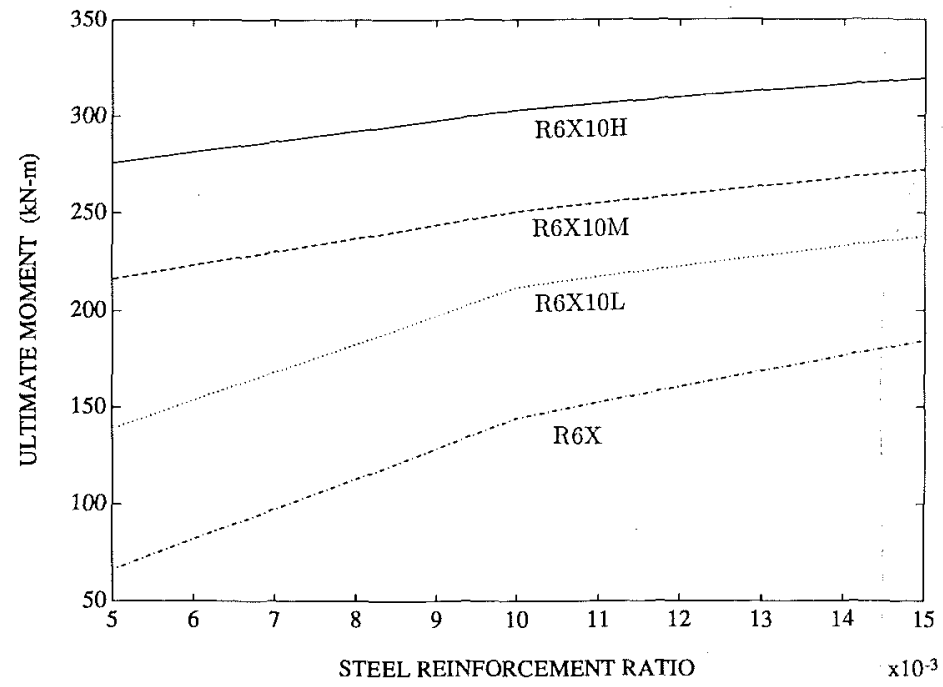

FIG. 11. Ultimate Moment versus Steel Reinforcement Ratio (Rectangular Beam)

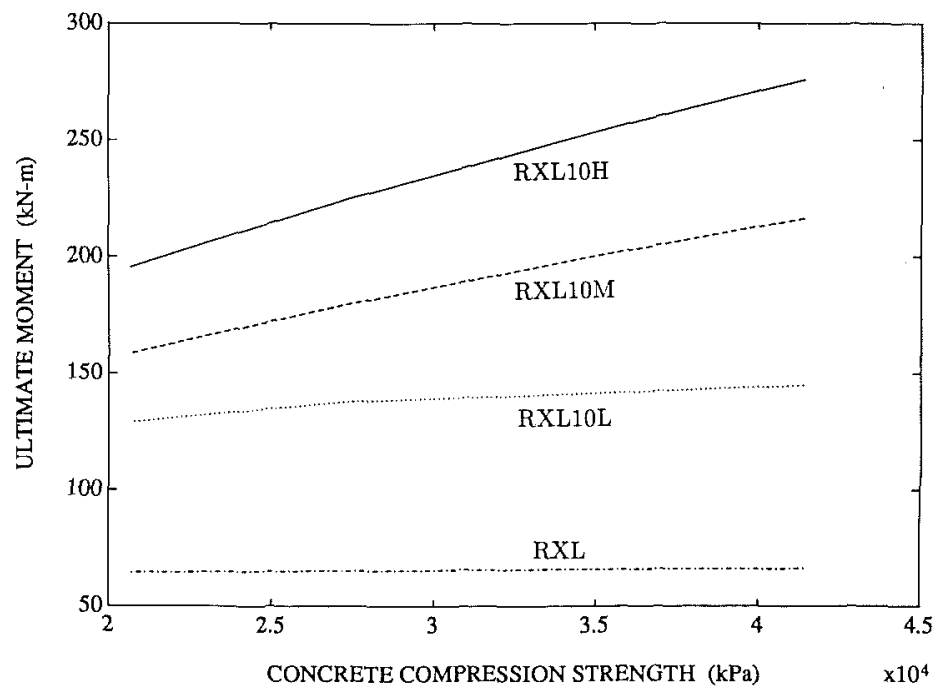

FIG. 12. Ultimate Moment versus Concrete Compressive Strength (Rectangular Beam) 


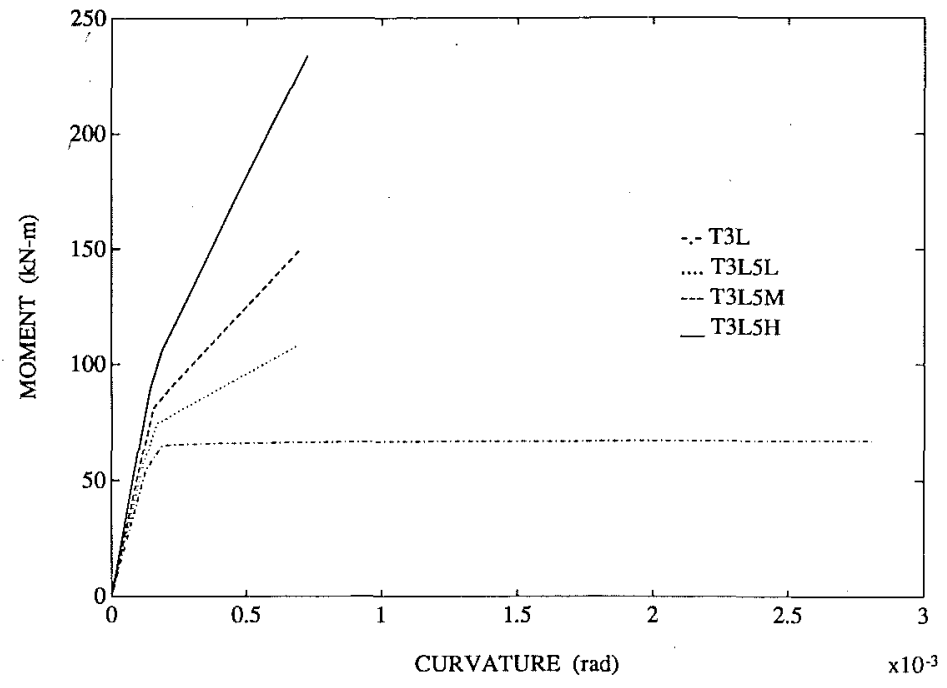

FIG. 13. Moment versus Curvature (Beams T3L, T3L5L, T3L5M, and T3L5H)

versus the ratio of plate area to gross concrete section. The dashed lines represent the beam with composite plate having a modulus of elasticity $=$ $E_{p}=34.5 \mathrm{GPa}(5,000 \mathrm{ksi})$ and ultimate strength $F_{p}=414 \mathrm{MPa}$ (60 ksi). The solid line represents the beam behavior with composite plate having $E_{p}=68.9 \mathrm{GPa}(10,000 \mathrm{ksi})$ and $F_{p}=828 \mathrm{MPa}(120 \mathrm{ksi})$. Five different plate-area ratios were used for each curve, i.e., $A_{p t} / b h=0,0.0025,0.005$, 0.010 , and 0.015 . Fig. 15 shows that the ultimate capacity of the beam increases substantially for both types of composite plate; however, the rate of increase in the moment capacity decreases with the increasing plate-area ratio.

The effect of steel reinforcement ratio on the ultimate moment of the section is shown in Fig. 16. The behavior is very similar to that of the rectangular section, as can be seen from the figure. The ultimate moment increases as the reinforcement ratio increases; however, the rate of increase of moment capacity decreases with an increase in the reinforcement ratio. Fig. 17 shows the relationship between the ultimate moment and concrete compressive strength. The increase in the concrete compressive strength had negligible effect on the moment capacity of the section with no plate. Inceasing the compression strength of concrete for the sections with the composite plate attached to the tension face resulted in only a slight increase in the moment capacity.

\section{Conclusions}

The analytical models based on the compatibility of deformations and equilibrium of forces presented reasonably approximate the behavior of concrete beams externally reinforced with epoxy-bonded fiber composite plates when a tough epoxy is used to ensure the transfer of force from the composite plate to the concrete beam. The composite plate, bonded to the tension face of the beam, increases the stiffness, yield moment, and ultimate 


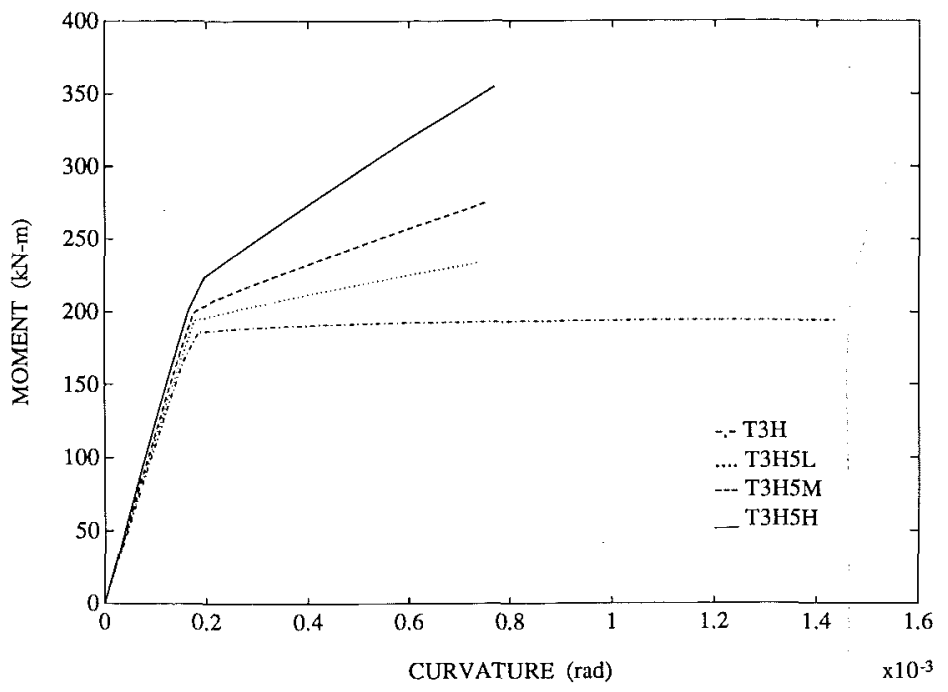

FIG. 14. Moment versus Curvature (Beams T3H, T3H5L, T3H5M, and T3H5H)

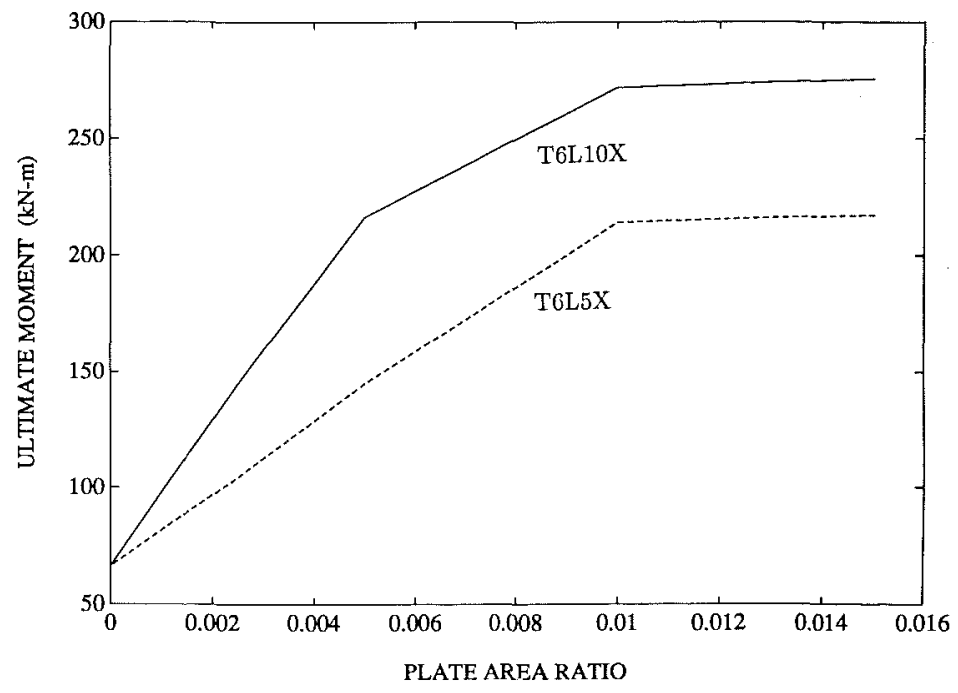

FIG. 15. Ultimate Moment versus Ratio of Plate Area to Gross Concrete Area (TBeam) 


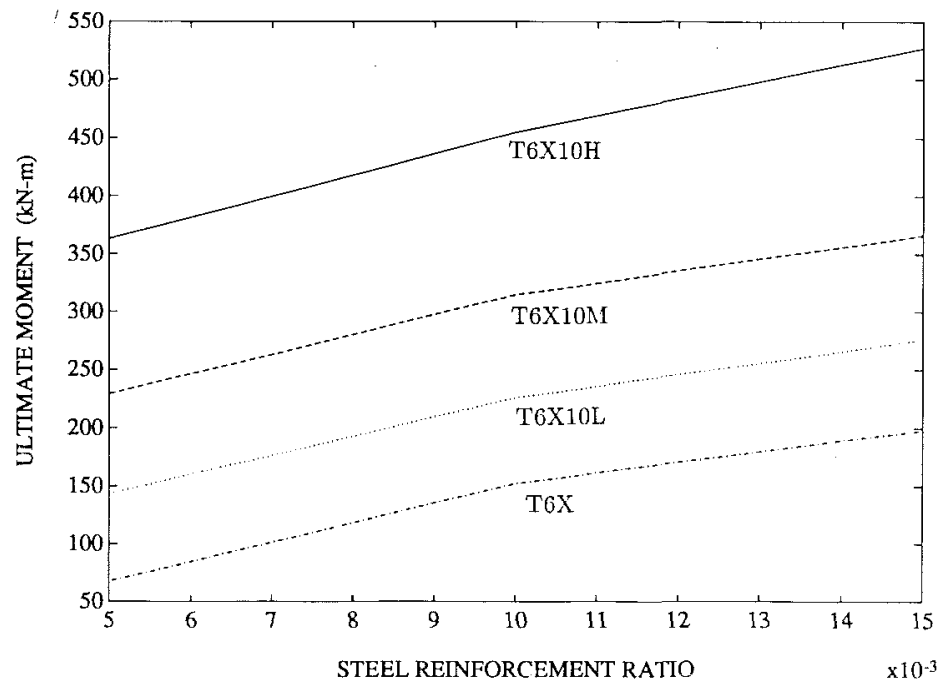

FIG. 16. Ultimate Moment versus Steel Reinforcement Ratio (T-Beam)

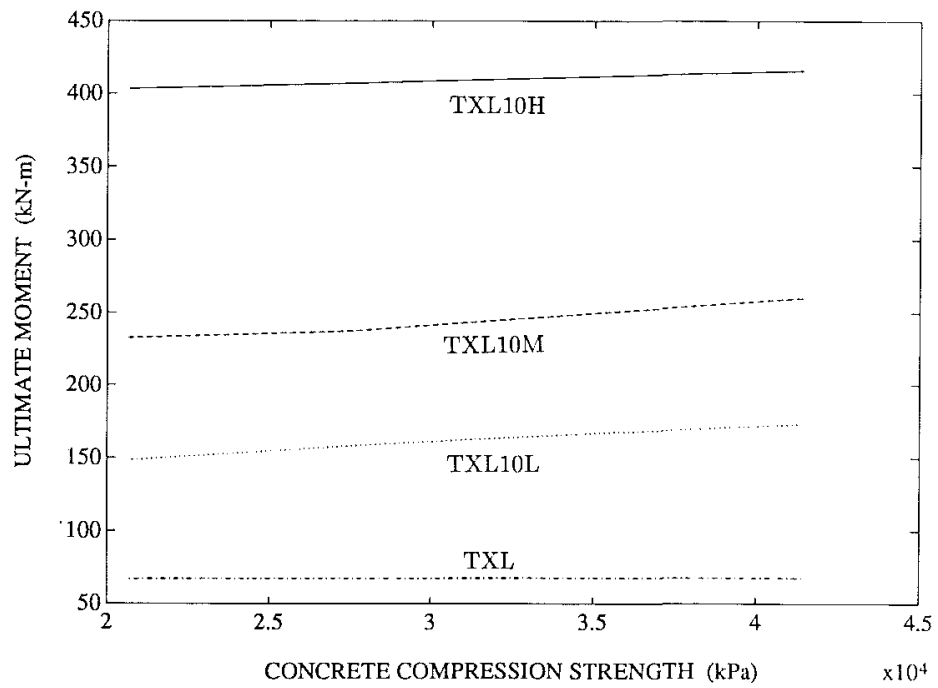

FIG. 17. Ultimate Moment versus Concrete Compressive Strength (T-Beam) 
moment of the beam and reduces the curvature at failure. The results of the parametric study indicate that the technique of strengthening existing concrete beams with epoxy-bonded composite plates is particularly effective in beams with a relatively low steel reinforcement ratio. Increasing the compressive strength of concrete did not appreciably increase the ultimate moment of the beam without the composite plate; however, in combination with the composite plate, an increase in the compressive strength of concrete increased the ultimate moment of the section. Because of fully elastic behavior of the composite plate and the low plate and concrete ductilities, failure can be reached as a result of rupture of plate, crushing of concrete in compression, or failure of the concrete layer between the plate and reinforcing bars. The latter case should be investigated further to develop a rational approach for predicting the load causing this type of failure.

\section{Appendix I. References}

Klaiber, F. W., Dunker, K. F., Wipf, T. J., and Sanders, W. W. (1987). "Methods of strengthening existing highway bridges." Report No. 293, National Cooperative Highway Research Program.

Oehlers, D. J. (1988). "Reinforced concrete beams with steel plates glued to their soffits: Prevention of plate separation induced by flexural peeling." Report No. R80, Dept. of Civil Enginering, University of Adelaide, Adelaide, Australia.

Hamoush, S. A., and Ahmad, S. H. (1990). "Debonding of steel-plate-strengthened concrete beams." J. Struct. Engrg., ASCE, 116(2), 356-371.

Park, R., and Paulay, T. (1975). Reinforced concrete structures. John Wiley and Sons, Inc., New York, N.Y.

Saadatmanesh H., and Ehsani, M. R. (1991). "RC beams strengthened with GFRP plates. I: Experimental Study." J. Struct. Engrg., ASCE, 117(11).

\section{Appendix II. Notation}

The following symbols are used in this paper:

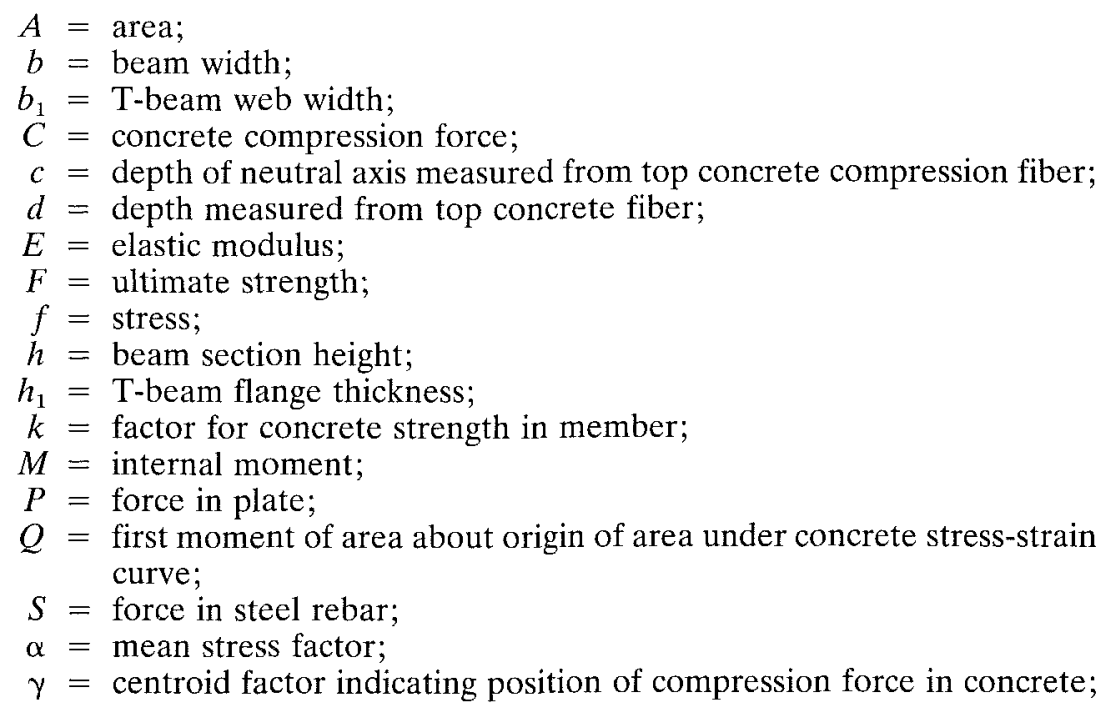


$\varepsilon=$ strain; and

$\bar{\varepsilon}=$ strain at centroid of area.

\section{Subscripts}

$c=$ concrete;

$c_{1}=$ compression force in web of T-beam;

$c_{2}=$ compression force in flange of T-beam;

$c f=$ concrete top fiber;

$f=$ flange;

$h_{1}=$ junction of web and flange of T-beam;

$i=$ level of steel rebar;

$o=$ maximum concrete stress;

$p l=$ plate;

$s i=$ steel;

$u=$ ultimate

$w=w e b ;$ and

$y=$ yield.

\section{Superscripts}

$'=$ compressive strength of concrete in test cylinder; and

$"=$ compressive strength of concrete in a member. 